\title{
Classical Neurotransmitters and Neuropeptides involved in Parkinson's Disease: A Multi-Neurotransmitter System
}

\author{
Felix-Martin Werner ${ }^{1,2^{*}}$ and Rafael Coveñas ${ }^{2}$ \\ ${ }^{1}$ Higher Vocational School for Elderly Care and Occupational Therapy, The Euro Akademie Pößneck, Germany
}

${ }^{2}$ Institute of Neurosciences of Castilla and León (INCYL), Laboratory of Neuroanatomy of the Peptidergic Systems (Lab. 14), University of Salamanca, Salamanca, Spain

*Corresponding author: Felix-Martin Werner, Institute of Neurosciences of Castilla and León (INCYL), Laboratory of Neuroanatomy of the Peptidergic Systems (Lab. 14 c/ Pintor Fernando Gallego, 137007-Salamanca, Spain, Tel: +34923294400; extension 1856; Fax: +34923294549; E-mail: felixm-werner@versanet.de

Rec date: Jun 20, 2014, Acc date: Jul 23, 2014, Pub date: Jul 25, 2014

Copyright: $\odot 2014$ Werner FM, et al. This is an open-access article distributed under the terms of the Creative Commons Attribution License, which permits unrestricted use, distribution, and reproduction in any medium, provided the original author and source are credited.

\begin{abstract}
Parkinson's disease is a neurodegenerative disease with motor and non-motor symptoms. In Parkinson's disease, a neurotransmitter imbalance occurs in the extrapyramidal system with a dopamine and GABA deficiency and an acetylcholine and glutamate surplus. Other classical neurotransmitters such as serotonin, the neuroactive substance adenosine and neuropeptides such as dynorphin and substance $P$ are also involved in the pathophysiology of the disease. Here, we describe the alterations of the involved neuroactive substances and the relationships between them in the extrapyramidal system. From the findings previously reported in the literature, here a neural network is developed in the extrapyramidal system. Additional anti-Parkinsonian drugs and their actions in the neural network are also pointed out, since a multimodal pharmacotherapy of the disease might improve its outcome.
\end{abstract}

Keywords: Parkinson's disease; Extrapyramidal system; Neural network; Dopamine; Serotonin; ABA, glutamate; Neuropeptides

\section{Introduction}

Parkinson's disease (PD) is a neurodegenerative disease that affects up to $1 \%$ of the people older than 60 years, more often men than women [1]. Meanwhile, it is known that $40 \%$ of the Parkinsonian patients develop dementia and $80 \%$ of them suffer from mild cognitive impairment [2]. An anti-Parkinsonian pharmacotherapy is started when the cardinal symptoms akinesia, rigidity and tremor appear. In $\mathrm{PD}$, the above mentioned symptoms occur if dopamine (DA) deficiency is up to $80 \%$ in the substantia nigra pars compacta and in the basal ganglia, i.e. the putamen and the caudate nucleus [2]. However, other classical neurotransmitters such as acetlycholine, glutamate and GABA also play a role in the pathophysiology of the disease. In fact, a neurotransmitter imbalance exists in the extrapyramidal system with a DA and GABA deficiency and an acetylcholine and glutamate surplus. In this sense, DA and acetylcholine act as postsynaptic excitatory neurotransmitters: DA exerts its effect upon D1 and D2 receptors and acetylcholine upon muscarinic and nicotinic cholinergic subreceptors [3]. Besides, via GABAA receptors, GABA exerts a reduced presynaptic inhibitory function and glutamate exerts an excitotoxic effect and a presynaptic inhibitory action via NMDA and metabotropic glutaminergic receptors [3]. Neuropeptides are as well involved in the pathophysiology of $\mathrm{PD}[4,5]$. In this sense, neurotensin and cholecystokinin show increased levels in the extrapyramidal system, and dynorphin and substance $\mathrm{P}$ have decreased levels [2]. The relationship between the formation of Lewy bodies containing alphasynuclein and the development of dementia will be also pointed out [6]. Considering the current available literature, here a neural network in the extrapyramidal system is developed. This network acts as a multi-neurotransmitter system. From the neural network suggested, it can be concluded that a multimodal pharmacotherapy could be efficacious in the treatment of the disease, and that the therapeutic efficacy of additional therapeutic options, such as $\mathrm{A}_{2 \mathrm{~A}}$ adenosine antagonists, subtype 5 of metabotropic glutaminergic receptor (m5GluR) antagonists or $5-\mathrm{HT}_{2 \mathrm{~A}}$ antagonists might be taken into consideration $[7,8]$.

\section{Alterations of classical neurotransmitters and neuropeptides in Parkinson's disease}

In $\mathrm{PD}$, in the extrapyramidal system, a neurotransmitter imbalance between dopaminergic and muscarinic cholinergic neurons occurs as well as between GABAergic and glutaminergic neurons. Here, in order to develop a neural network, the alterations of adenosine and classical neurotransmitters (e.g., DA, acetylcholine, serotonin (5-HT), GABA, glutamate) are described. Moreover, the alterations of neuropeptides (cholecystokinin, dynorphin, neurotensin, substance $\mathrm{P}$ ) are described.

\section{Dopamine}

In $\mathrm{PD}$, the loss of dopaminergic neurons in the substantia nigra pars compacta is due to the oxidative stress and partly to the susceptibility genes [6]. Alpha-synuclein could be detected in the perikarya and processes of dopaminergic neurons, in which Lewy bodies can be found [6]. In the basal ganglia, it has been reported that not only dopaminergic neurons, but also muscarinic cholinergic neurons, GABAergic neurons and glutaminergic neurons are involved in a neural network [9]. After treatment of PD with 1-dopa or dopamine agonists, the Parkinsonian motor symptoms improved, however dyskinesia occurred. An additional administration of MAO-B (monoamine oxidse B) or COMT (catechol O-methyl transferase) inhibitors or of non-dopaminergic agents showed a therapeutic effect upon dyskinesias [10]. 
Citation: Werner FM, Covenas R (2014) Classical Neurotransmitters and Neuropeptides involved in Parkinson's Disease: A MultiNeurotransmitter System. J Cytol Histol 5: 266. doi:10.4172/2157-7099.1000266

Page 2 of 5

\section{Acetylcholine}

In $\mathrm{PD}$, a dopaminergic-cholinergic neurotransmitter imbalance occurs between DA deficiency, via D2 receptors, and a surplus of muscarinic cholinergic neurons via M4 receptors [11]. Scopolamine (subcutaneous injection), an antagonist of muscarinic cholinergic receptors was used to treat a Parkinsonian patient who could no longer take an oral medication [12]. Dopaminergic and muscarinic cholinergic neurons exert an antagonistic interaction between each other, which is enabled through presynaptic GABAergic neurons via GABAA receptors and glutaminergic neurons via NMDA receptors. However, nicotinic cholinergic (nAch) neurons partly activate dopaminergic neurons [11]. NAch neurons activate dopaminergic neurons in the putamen via $\beta 2$ receptors. Thus, $B 2$ nAch agonists could be of therapeutic value in the treatment of PD [13]. Forty percent of Parkinsonian patients develop dementia. This could be due to the cholinergic loss in the nucleus basalis of Meynert, where the inputs to the cerebral cortex are originated [14].

\section{Serotonin}

In 1-dopa treated 6-hydroxy-dopamine lesioned rats, the 5-HT hyperactivity in the striatum and the caudate nucleus is associated with dyskinesias. In this sense, DA loss is compensated by $5-\mathrm{HT}$ hyperactivity [15]. It has been showed a dopaminergic-serotonergic interaction in the putamen through glutaminergic neurons via NMDA receptors and that 5-HT exerts its function via $5-\mathrm{HT}_{2 \mathrm{~A}}$ receptors [16]. A question arises, whether $5-\mathrm{HT}_{2 \mathrm{~A}}$ antagonists could have antiParkinsonian properties and could improve 1-dopa induced dyskinesias [16]. An additional administration of 5- $\mathrm{HT}_{2 \mathrm{~A}}$ antagonists could not only improve dyskinesias, but also improve psychotic symptoms [16].

\section{GABA}

GABA exerts a presynaptic inhibitory function in the globus pallidus internus and externus and in the striatum via $\mathrm{GABA}_{\mathrm{A}}$ and $\mathrm{GABA}_{\mathrm{B}}$ receptors [17]. While the globus pallidus internus is an output nucleus, the globus pallidus externus is an input nucleus [17]. DA deficiency is enhanced by the GABA hypofunction, while there is an antagonistic interaction between AMPA/NMDA glutaminergic neurons and $\mathrm{GABA}_{\mathrm{A}}$ receptors [18]. Drugs enhancing GABAergic neurotrasmission with an agonistic effect at $\mathrm{GABA}_{\mathrm{A}}$ receptors could be of therapeutic value in the treatment of PD.

\section{Glutamate}

In $\mathrm{PD}$ exists a GABAergic glutaminergic neurotransmitter imbalance in the extrapyramidal system with a GABA deficiency and a glutamate hyperactivity or excitotoxicity [4]. In the putamen, glutaminergic neurons could strongly inhibit presynaptically $\mathrm{D}_{2}$ dopaminergic neurons via NMDA receptors and thus these neurons could enhance DA deficiency [3,4]. NMDA antagonists have antidyskinetic effects [19]. Metabotropic glutaminergic neurons are also of importance in the treatment of PD [20]. In this sense, antagonists of m5GluR (e.g., 3-[(2-methyl-1,3-thiazol-4-yl)ethynyl] pyridine) have a protective effect on dopaminergic neurons and ameliorate Parkinsonian motor symptoms [20]. In the putamen, metabotropic glutaminergic neurons, which are strongly activated by adenosine neurons via A2A receptors, could strongly inhibit dopaminergic neurons via m5Glu receptors (Figure 1).

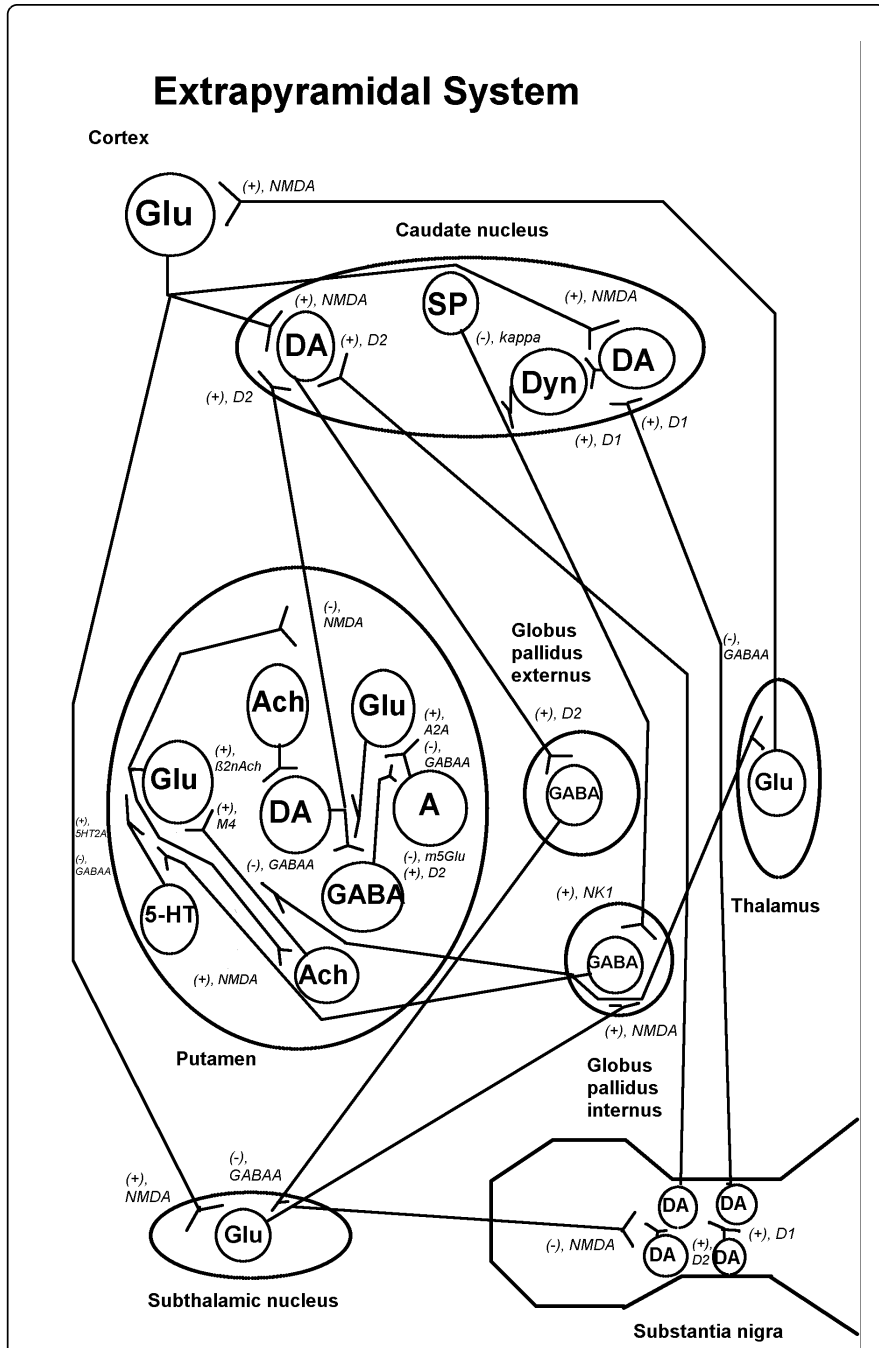

Figure 1: Neural networks, classical neurotransmitters and neuropeptides involved in Parkinson's disease. Ach: acetylcholine; A: adenosine; A2A: a subreceptor of the adenosine receptor; ß2nAch: a subreceptor of the nicotinic cholinergic receptor; DA: dopamine; D1: $\mathrm{D}_{1}$ receptor, a subreceptor of the dopamininergic receptor; $\mathrm{D} 2: \mathrm{D}_{2}$ receptor, a subreceptor of the dopamininergic receptor; Dyn: dynorphin; GABA: gamma-aminobutyric acid; GABAA: $\mathrm{GABA}_{\mathrm{A}}$ receptor, a subreceptor of the GABAergic receptor; Glu: glutamate; 5-HT: serotonin; 5-HT2A: 5- $\mathrm{HT}_{2 \mathrm{~A}}$ receptor, a subreceptor of the serotonergic receptor; kappa: a subreceptor of the dynorphin receptor; m5Glu: m5Glu receptor, a subreceptor of the metabotropic glutaminergic receptor; NK1: a subreceptor of the tachykinin receptor; NMDA: N-methyl-Daspartate receptor; SP: substance P. A plus mark indicates a postsynaptic excitatory impulse, and a minus mark indicates a presynaptic inhibitory impulse.

\section{Cholecystokinin}

In 6-hydroxy-dopamine lesioned rats, alterations in the level of some neuropeptides have been found. In this sense, cholecystokinin (CCK) levels have been reported to be increased in the striatum [21]. It 
Page 3 of 5

is known that, in contrast to $\mathrm{CCK}_{\mathrm{A}}$ antagonists, antagonists of the $\mathrm{CCK}_{\mathrm{B}}$ receptor could exert beneficial therapeutic effects [22].

\section{Dynorphin}

In the substantia nigra exists an inverse correlation between DA deficiency and the increased activity of dynorphin neurons which show a high affinity for both mu and/or delta opioid receptors [23]. In the neural network suggested here, it will be shown that dynorphin neurons in the caudate nucleus receive a weak activating input from the $\mathrm{D}_{1}$ dopaminergic neurons located in the substantia nigra, and that these dynorphinergic neurons via kappa receptors presynaptically inhibit substance P neurons [5].

\section{Neurotensin}

It has been described in PD an increased activity of neurotensin in the striatum which enhances both the excitotoxicity of glutamate, via NMDA receptors, and the DA deficiency [24]. In the future, it should be examined whether $\mathrm{NTS}_{1}$ receptor antagonists could exert a beneficial therapeutic effect in the treatment of PD [25].

\section{Substance $\mathbf{P}$}

Substance $\mathrm{P}$ is an undepeptide belonging to the tachykinin family of peptides and mainly exerts its function via the $\mathrm{NK}_{1}$ receptor. In the substantia nigra, the release of DA and the concentration of substance $\mathrm{P}$ are positively correlated [26]. In the neural network presented here, substance P-containing neurons in the caudate nucleus, which are inhibited by dynorphin neurons via kappa receptors, weakly activate GABAergic neurons located in the globus pallidus internus [27].

\section{Other neuroactive substances: adenosine}

Adenosine is a neuroactive substance located in the basal ganglia which influences the release of GABA and acetylcholine [28]. Adenosine $\mathrm{A}_{2 \mathrm{~A}}$ antagonists have been proved to ameliorate motor symptoms in PD without worsening dyskinesias [28]. In the putamen, an antagonistic interaction between $\mathrm{D}_{2}$ dopaminergic neurons and $\mathrm{A}_{2 \mathrm{~A}}$ adenosine neurons occurs: $\mathrm{A}_{2 \mathrm{~A}}$ adenosine neurons strongly activate glutaminergic neurons which strongly inhibit $D_{2}$ dopaminergic neurons via m5GluR. The $\mathrm{D}_{2}$ dopaminergic neurons weakly activate GABAergic neurons which, via $\mathrm{GABA}_{\mathrm{A}}$ receptors, inhibit adenosine neurons [29].

\section{Alpha-synuclein formation and dementia in Parkinson's disease}

In PD, Lewy bodies containing A53T alpha-synuclein have been described [30]. It has been reported that reduced DA levels are correlated with the overexpression of alpha-synuclein [30]. Mice with an overexpression of A53T alpha-synuclein showed a reduced neurogenesis in the olfactory bulb and the substantia nigra [31].

Forty percent of the patients with PD develop dementia and $85 \%$ of these patients show a mild cognitive impairment [14]. DA deficiency in the substantia nigra pars compacta causes the motor symptoms, whereas acetylcholine deficiency which starts in the nuclues basalis of Meynert can induce dementia symptoms [14]. The appropriate treatment of dementia in Parkinson's disese is the administration of rivastagmine, a cholinesterase inhibitor which increases acetylcholine levels [32].

\section{Neural networks in the extrapyramidal system}

The basal ganglia are characterized by their complex neural networks. The following nuclei, namely the striatum (caudate nucleus and putamen), the subthalamic nucleus, the external and internal globus pallidus and the substantia nigra are involved in these neural networks [33]. According to the available literature $[3,4,11,13,16,19,20,26-28,33,34]$, the neural networks can be described as follows (see Figure 1). In the substantia nigra pars compacta, dopaminergic neurons via $\mathrm{D}_{1}$ and $\mathrm{D}_{2}$ receptors send projections to dopaminergic neurons located in the caudate nucleus. The $D_{1}$ dopaminergic neurons weakly activate dynorphin neurons which presynaptically inhibit via kappa receptors substance $\mathrm{P}$ neurons. The latter neurons transmit a weak activiting impulse via $\mathrm{NK}_{1}$ receptor to GABAergic neurons in the globus pallidus internus [26]. The $\mathrm{D}_{2}$ dopaminergic neurons located in the caudate nucleus weakly activate GABAergic neurons in the globus pallidus externus which weakly inhibit, via $\mathrm{GABA}_{\mathrm{A}}$ receptors, glutaminergic neurons located in the nucleus subthalamicus [34]. The latter neurons strongly inhibit dopaminergic neurons in the substantia nigra and thus enhance DA deficiency. Besides, they activate GABAergic neurons in the globus pallidus internus. The GABAergic neurons in this nucleus inhibit presynaptically glutaminergic neurons in the thalamus which activate other glutaminergic neurons located in the cortex. The cortical glutaminergic neurons activate, via NMDA receptors, $D_{1}$ and $D_{2}$ dopaminergic neurons located in the caudate nucleus and glutaminergic neurons located in the nucleus subthalamicus [19]. The GABAergic neurons in the globus pallidus internus inhibit presynaptically, via $\mathrm{GABA}_{\mathrm{A}}$ receptors, muscarinic cholinergic and serotonergic neurons in the putamen. These muscarinic cholinergic and serotonergic neurons transmit a strong activating impulse via $\mathrm{M}_{4}$ and $5-\mathrm{HT}_{2 \mathrm{~A}}$ receptors to glutaminergic neurons which strongly inhibit $\mathrm{D}_{2}$ dopaminergic neurons via NMDA receptors $[11,16]$. Nicotinic cholinergic neurons weakly activate dopaminergic neurons via $B_{2}$ receptors, and adenosine neurons activate via $A_{2 A}$ receptors glutaminergic neurons which, via the subtype 5 of metabotropic glutaminergic neurons, strongly inhibit $\mathrm{D}_{2}$ dopaminergic neurons [ 13 , $20,28]$. The $D_{2}$ dopaminergic neurons in the putamen are connected to other $\mathrm{D}_{2}$ dopaminergic neurons located in the caudate nucleus.

\section{Additional therapeutic options in the treatment of Parkinson's disease}

In addition to l-dopa combined with a decarboxylase inhibitor, the following anti-Parkinsonian drugs could also be administered according to the neural networks described: DA agonists, inhibitors of enzymes degrading DA (e.g. $\mathrm{MAO}(\mathrm{B})$ and COMT inhibitors), $\mathrm{M}_{4}$ antagonists and NMDA antagonists.

In the future, it should be also examined whether additional antiParkinsonian pharmacotherapies could be applied, for example:

- m5GluR antagonists, which increase DA levels through a reduced presynaptic inhibition [20].

- $\mathrm{A}_{2 \mathrm{~A}}$ adenosine antagonists, which reduce the glutaminergic presynaptic inhibition of dopaminergic neurons via m5Glu receptors [28].

- $\beta_{2}$ nAch agonists, which stimulate the $\beta_{2}$ subreceptor of nicotinic cholinergic receptors and also activate dopaminergic neurons in the putamen [13].

- $5-\mathrm{HT}_{2 \mathrm{~A}}$ antagonists, which block the $5-\mathrm{HT}_{2 \mathrm{~A}}$ subreceptor of serotonergic neurons in the putamen, reduce the glutaminergic 
presynaptic inhibition of dopaminergic neurons via NMDA receptors and ameliorate dyskinesias by counteracting $\mathrm{D}_{2} \mathrm{DA}$ deficiency. Besides $5-\mathrm{HT}_{2 \mathrm{~A}}$ antagonists have a slight antipsychotic effect [16].

\section{Conclusion}

We have focused our review on the alterations of classical neurotransmitters (DA, acetylcholine, 5-HT, GABA, glutamate), adenosine and neuropeptides (cholecystokinin, dynorphin, neurotensin, substance P) in PD and we have also reported the functional relationships between them. In the extrapyramidal system, neural networks have been developed and the relationships between the mentioned neuroactive substances and the existing dopaminergiccholinergic and GABAergic-glutaminergic neurotransmitter imbalances have been taken into consideration. The neural networks suggested here have been taken from the results published in laboratory animals and they still need to be confirmed in humans. In the neural networks, 5-HT hyperactivity via $5-\mathrm{HT}_{2 \mathrm{~A}}$ receptors, glutamate excitotoxicity via $\mathrm{m} 5 \mathrm{Glu}$ receptors, adenosine hyperactivity via $A_{2 A}$ receptors and acetylcholine hypoactivity via $n A c h \beta_{2}$ receptors are included. Since a multimodal pharmacotherapy can improve the course of the disease, some additional pharmacological options are mentioned and justified according to the suggested neural networks. Two examples of a multimodal anti-Parkinsonian pharmacotherapy could be given: It could be possible to combine l-dopa or dopamine agonists with $\mathrm{A}_{2 \mathrm{~A}}$ adenosine antagonists and m5GluR antagonists or to combine l-dopa or dopamine agonists with NMDA antagonists and $5-\mathrm{HT}_{2 \mathrm{~A}}$ antagonists. In the second example, these combined antiParkinsonian drugs have a synergistic effect. NMDA antagonists could cause psychotic symptoms as an adverse effect, while $5-\mathrm{HT}_{2 \mathrm{~A}}$ antagonists exert a slight antipsychotic effect. It remains to be examined the clinical efficacy of such drugs and to investigate in-depth the neural networks suggested in the extrapyramidal system.

\section{References}

1. Werner FM, Coveñas R (2005) Classical neurotransmitters and neuropeptides involved in Parkinson's Disease. Curr Top Prot Pept Res 4: 75-84.

2. Varanese S1, Birnbaum Z, Rossi R, Di Rocco A (2011) Treatment of advanced Parkinson's disease. Parkinsons Dis 2010: 480260.

3. Werner FM (2007) Classical neurotransmitters involved in Parkinson's disease. J Neural Transm 114: I-XXXI.

4. Werner FM, Coveñas R (2011) Classical neurotransmitters and neuropeptides involved in generalized epilepsy: a focus on antiepileptic drugs. Curr Med Chem 18: 4933-4948.

5. Werner FM, Coveñas R (2012) Possible therapeutic options in Parkinson's disease according to a neuronal network. Neurologie \& Rehabilitation 18: 420-421.

6. Tapia-González S, Giráldez-Pérez RM, Cuartero MI, Casarejos MJ, Mena MÁ, et al. (2011) Dopamine and Ît-synuclein dysfunction in Smad3 null mice. Mol Neurodegener 6: 72.

7. Grégoire L, Morin N, Ouattara B, Gasparini F, Bilbe G, et al. (2011) The acute antiparkinsonian and antidyskinetic effect of AFQ056, a novel metabotropic glutamate receptor type 5 antagonist, in L-Dopa-treated parkinsonian monkeys. Parkinsonism Relat Disord 17: 270-276.

8. Ansah TA, Ferguson MC, Nayyar T (2011) The 5-HT(2A) Receptor Antagonist M100907 Produces Antiparkinsonian Effects and Decreases Striatal Glutamate. Front Syst Neurosci 5: 48.

9. Rice ME, Patel JC, Cragg SJ (2011) Dopamine release in the basal ganglia. Neuroscience 198: 112-137.
10. Lieu CA, Subramanian T (2012) The interhemispheric connections of the striatum: Implications for Parkinson's disease and drug-induced dyskinesias. Brain Res Bull 87: 1-9.

11. Aosaki T, Miura M, Suzuki T, Nishimura K, Masuda M (2010) Acetylcholine-dopamine balance hypothesis in the striatum: an update. Geriatr Gerontol Int 10 Suppl 1: S148-157.

12. Pérez LM, Farriols C, Puente V, Planas J, Ruiz I (2011) The use of subcutaneous scopolamine as a palliative treatment in Parkinson's disease. Palliat Med 25: 92-93.

13. Huang LZ, Grady SR, Quik M (2011) Nicotine reduces L-DOPA-induced dyskinesias by acting at beta2 ${ }^{\star}$ nicotinic receptors. J Pharmacol Exp Ther 338: 932-941.

14. Yarnall A, Rochester L, Burn DJ (2011) The interplay of cholinergic function, attention, and falls in Parkinson's disease. Mov Disord 26: 2496-2503.

15. Bédard C, Wallman MJ, Pourcher E, Gould PV, Parent A, et al. (2011) Serotonin and dopamine striatal innervation in Parkinson's disease and Huntington's chorea. Parkinsonism Relat Disord 17: 593-598.

16. Paul J, Kuruvilla KP, Mathew J, Kumar P, Paulose CS (2011) Dopamine Dâ, and D receptor subtypes functional regulation in cerebral cortex of unilateral rotenone lesioned Parkinson's rat model: Effect of serotonin, dopamine and norepinephrine. Parkinsonism Relat Disord 17: 255-259.

17. Jaeger D, Kita H (2011) Functional connectivity and integrative properties of globus pallidus neurons. Neuroscience 198: 44-53.

18. Bosch C, Degos B, Deniau JM, Venance L (2011) Subthalamic nucleus high-frequency stimulation generates a concomitant synaptic excitationinhibition in substantia nigra pars reticulata. J Physiol 589: 4189-4207.

19. Kobylecki C, Hill MP, Crossman AR, Ravenscroft P (2011) Synergistic antidyskinetic effects of topiramate and amantadine in animal models of Parkinson's disease. Mov Disord 26: 2354-2363.

20. Masilamoni GJ, Bogenpohl JW, Alagille D, Delevich K, Tamagnan G, et al. (2011) Metabotropic glutamate receptor 5 antagonist protects dopaminergic and noradrenergic neurons from degeneration in MPTPtreated monkeys. Brain 134: 2057-2073.

21. Nilsson A, Fälth M, Zhang X, Kultima K, Sköld K, et al. (2009) Striatal alterations of secretogranin-1, somatostatin, prodynorphin, and cholecystokinin peptides in an experimental mouse model of Parkinson disease. Mol Cell Proteomics 8: 1094-1104.

22. Boyce S1, Rupniak NM, Tye S, Steventon MJ, Iversen SD (1990) Modulatory role for CCK-B antagonists in Parkinson's disease. Clin Neuropharmacol 13: 339-347.

23. Ljungdahl A, Hanrieder J, Fälth M, Bergquist J, Andersson M (2011) Imaging mass spectrometry reveals elevated nigral levels of dynorphin neuropeptides in L-DOPA-induced dyskinesia in rat model of Parkinson's disease. PLoS One 6: e25653.

24. Antonelli T1, Tomasini MC, Finetti S, Giardino L, Calzà L, et al. (2002) Neurotensin enhances glutamate excitotoxicity in mesencephalic neurons in primary culture. J Neurosci Res 70: 766-773.

25. Ferraro L, Tomasini MC, Beggiato S, Guerrini R, Salvadori S, et al. (2009) Emerging evidence for neurotensin receptor 1 antagonists as novel pharmaceutics in neurodegenerative disorders. Mini Rev Med Chem 9: 1429-1438.

26. Thornton E, Tran TT, Vink R (2010) A substance P mediated pathway contributes to 6-hydroxydopamine induced cell death. Neurosci Lett 481 : 64-67.

27. Werner F, Coveñas R (2013) Zusätzliche pharmakologische Möglichkeiten beim Morbus Parkinson anhand eines neuronalen Netzwerkes. Neurologie \& Rehabilitation 6: 397-398.

28. Jenner P (2003) A2A antagonists as novel non-dopaminergic therapy for motor dysfunction in PD. Neurology 61: S32-38.

29. Fuxe K, Agnati LF, Jacobsen K, Hillion J, Canals M, et al. (2003) Receptor heteromerization in adenosine $\mathrm{A} 2 \mathrm{~A}$ receptor signaling: relevance for striatal function and Parkinson's disease. Neurology 61: S19-23. 
Citation: Werner FM, Covenas R (2014) Classical Neurotransmitters and Neuropeptides involved in Parkinson's Disease: A MultiNeurotransmitter System. J Cytol Histol 5: 266. doi:10.4172/2157-7099.1000266

Page 5 of 5

30. Kurz A, Double KL, Lastres-Becker I, Tozzi A, Tantucci M, et al. (2010) A53T-alpha-synuclein overexpression impairs dopamine signaling and striatal synaptic plasticity in old mice. PLoS One 5: e11464

31. Peng J, Andersen JK (2011) Mutant $\alpha$-synuclein and aging reduce neurogenesis in the acute 1-methyl-4-phenyl-1,2,3,6-tetrahydropyridine model of Parkinson's disease. Aging Cell 10: 255-262.

32. Werner F-M, Coveñas R (2009) How to treat dementia in Parkinson's disease?. J Neural Transm 116: 233.
33. Miguelez C, Morera-Herreras T, Torrecilla M, Ruiz-Ortega JA, Ugedo L (2014) Interaction between the 5-HT system and the basal ganglia: functional implication and therapeutic perspective in Parkinson's disease. Front Neural Circuits 8: 21.

34. Gajcy K, Lochy $\AA$,ski S, Librowski T (2010) A role of GABA analogues in the treatment of neurological diseases. Curr Med Chem 17: 2338-2347. 